\title{
POTENCIAL POLUIDOR DE REJEITOS CARBONÍFEROS. II- EFEITOS DA RECUPERAÇÃO COM CAMADAS DE SOLO SOBRE AS PLANTAS E A POPULAÇÃO MICROBIANA ${ }^{1}$
}

\author{
POLLUTANT POTENCIAL OF COAL REJECTS. II- RECUPERATION EFFECTS \\ WITH SOIL LAYERS IN PLANTS AND MICROBIAL POPULATION
}

\author{
Larisa Ho Bech Gaivizzo ${ }^{2}$ Caio Vidor ${ }^{3}$ Marino José Tedesco ${ }^{4}$ \\ Carlos Alberto Bissani ${ }^{5}$
}

RESUMO

\begin{abstract}
A minimização do impacto sobre o ambiente advindo da mineração do carvão pode ser obtida pela recomposição topográfica da área minerada, seguida da cobertura dos rejeitos com uma camada de solo e de práticas de revegetação. Em vista disso, desenvolveu-se o presente trabalho com o objetivo de avaliar o efeito da adição de camadas de solo com diferentes espessuras aplicadas na superfície do rejeito carbonífero (RC), em posições de subsuperfície e do solo misturado ao rejeito sobre a produção de matéria seca das plantas de trevo-branco, milho e aveia-preta, e sobre a população microbiana. A utilização de uma camada de solo de $10 \mathrm{~cm}$ na superfície do $R C$ mostrou-se a mínima necessária ao estabelecimento de trevo e aveia. As culturas não apresentaram concentrações tóxicas de metais pesados. A elevada acidez do RC reduziu a densidade populacional de bactérias, actinomicetos e fungos, principalmente nas camadas de solo de subsuperficie.
\end{abstract}

Palavras-chave: revegetação, absorção de nutrientes, metais pesados.

\section{SUMMARY}

The landscape recomposition with soil layer and the introduction of plants have been used as an alternative to minimize the environmental impact caused by coal mining. The main concern for this practice is the low avaibility of soil from surface horizons and economic viability, consequently it is basic to determine the minimum soil layer thickness to be disposed on the reject. An experiment was carried out with addition of soil (Paleudult) layers with different thickness disposed on the surface of coal rejects, and in subsurface positions, and soil mixed with rejects, concerning effects on biomass yield of white clover (Trifolium repens $L_{\text {. }}$ ), corn (Zea mays L.), and oat (Avena strigosa $\mathbf{L}$.) as well as on soil microbial abundance. It was established that a soil layer of $10 \mathrm{~cm}$ thickness was the minimum necessary for clover and oat growth. Toxic concentrations of heavy metals in plants were not detected. However, soil microbial population represented by bacteria, fungi and actinomyces showed a lower density due to the high acidity that ocurred mainly in subsurface layers.

Key words: plant growth, nutrient uptake, heavy metals.

\section{INTRODUÇÃO}

As reservas brasileiras de carvão atingem 32 bilhões de toneladas, sendo que $87 \%$ encontramse no Rio Grande do Sul (SILVA, 1987). Apesar de importante recurso energético, a exploração mineral é responsável pela produção e pelo acúmulo desordenado de grandes volumes de rejeitos. As áreas utilizadas como depósito de rejeitos carboníferos são recuperadas através do nivelamento das pilhas (recomposição topográfica) e a cobertura da superfície com uma camada de solo.

\footnotetext{
${ }^{1}$ Parte da dissertação de mestrado em Ciência do Solo do primeiro autor, apresentada à Faculdade de Agronomia, Universidade Federal do Rio Grande do Sul (UFRGS), Porto Alegre, RS, em Junho de 1997. Trabalho financiado pelo CIAMB/CNPq.

${ }^{2}$ Engenheiro Agrônomo, Coordenadora da Área de Gestão Ambiental e do Curso de Engenharia de Bioprocessos e Biotecnologia, UFRGS. Rua: Gonçalves Dias, 603/305, 90130-061, Porto Alegre, RS. E-mail: larisaho@ zipmail.combr. Autor para correspondência. ${ }^{3}$ Professor Adjunto (aposentado), Departamento de Solos, Faculdade de Agronomia, UFRGS.

${ }^{4}$ Professor Titular, Departamento de Solos, Faculdade de Agronomia, UFRGS.

${ }^{5}$ Professor Adjunto, Departamento de Solos, UFRGS.
} 
O estabelecimento e a manutenção da comunidade de plantas após a recomposição topográfica e a cobertura do rejeito carbonífero com uma camada de solo podem minimizar em parte os impactos causados ao ambiente pelas áreas de mineração. A redução do fluxo de ar e água diminui a produção da drenagem ácida e os riscos de combustão espontânea das pilhas, além de promover a estabilização da superfície, controlando os processos erosivos e a sedimentação de partículas nos mananciais da região (DANIELS, 1996). No entanto, a pequena disponibilidade de solo dos horizontes superficiais e o custo de cobertura tornam fundamental a determinação da espessura mínima da camada de solo a ser aplicada sobre os rejeitos.

Vários fatores de natureza física e química do rejeito carbonífero limitam o estabelecimento vegetal, restringindo a reabilitação das áreas de mineração. A acidificação das pilhas de rejeitos devido à oxidação da pirita promove a solubilização de íons em níveis tóxicos para as plantas, inibe o crescimento de raízes e reduz o número de microrganismos fixadores de nitrogênio (TAYLOR $\boldsymbol{e t} \boldsymbol{a l} ., 1992)$. Conforme JOOST $\boldsymbol{e t} \boldsymbol{a l}$. (1987), os rejeitos carboníferos normalmente apresentam baixo $\mathrm{pH}$, elevada temperatura superficial, baixa capacidade de retenção de água, pequena disponibilidade de nitrogênio e presença de formas insolúveis de fósforo. Assim, o manejo adequado dos nutrientes, principalmente o $\mathrm{N}$ e o $\mathrm{P}$, e da água são fatores fundamentais a serem considerados em programas de recuperação de áreas de mineração (VIDOR, 1996). De acordo com DANIELS \& AMOS (1985), para que uma comunidade de plantas torne-se auto-sustentável é necessário o desenvolvimento de um eficiente ciclo de nutrientes. Durante os primeiros estádios da revegetação, a comunidade de plantas extrai grandes quantidades de nutrientes do solo e dos fertilizantes adicionados. Este processo continua até a construção de uma reserva orgânica, com a qual a absorção de nutrientes pelas plantas passa a depender dos processos de decomposição da cobertura e mineralização dos nutrientes, principalmente o $\mathrm{N}$ e o $\mathrm{P}$. Considerando que a produtividade a longo prazo do sistema solo/planta é dependente da acumulação de matéria orgânica, com respectivo aumento do balanço de N e P (DANIELS, 1996), pode-se perceber a importância da colonização e da atividade dos principais grupos de microrganismos (bactérias, fungos e actinomicetos) para os solos construídos em áreas de mineração.

Em vista disso, desenvolveu-se o presente trabalho com o objetivo de avaliar o efeito da adição de camadas de solo com diferentes espessuras na superfície do rejeito carbonífero, em posições de subsuperfície e do solo misturado ao rejeito sobre o crescimento de plantas de trevo-branco, milho e aveia-preta, e sobre a população microbiana.

\section{MATERIAL E MÉTODOS}

Os dados referentes à instalação e condução do experimento encontram-se descritos em GAIVIZZO et al. (2002), sendo que as unidades experimentais (tubos de PVC com $30 \mathrm{~cm}$ de diâmetro e $60 \mathrm{~m}$ de altura) são agora consideradas vasos de crescimento. $\mathrm{O}$ delineamento experimental adotado foi de blocos completos casualizados, com doze tratamentos e três repetições (camadas a partir da superfície): 1) $60 \mathrm{~cm}$ de solo (S); 2) $60 \mathrm{~cm}$ de rejeito carbonífero (RC); 3) $60 \mathrm{~cm}$ de $\mathrm{RC}+$ adubo PK; 4) $10 \mathrm{~cm}$ de $\mathrm{S}+1 \mathrm{~cm}$ de calcário $+49 \mathrm{~cm}$ de $\mathrm{RC} ; 5)$ $5 \mathrm{~cm}$ de $\mathrm{S}+55 \mathrm{~cm}$ de $\mathrm{RC}$; 6) $10 \mathrm{~cm}$ de $\mathrm{S}+50 \mathrm{~cm}$ de $\mathrm{RC}$; 7) $15 \mathrm{~cm}$ de $\mathrm{S}+45 \mathrm{~cm}$ de $\mathrm{RC}$; 8) $10 \mathrm{~cm}$ de $\mathrm{S}+$ $45 \mathrm{~cm}$ de mistura $1 \mathrm{~S}: 1 \mathrm{RC}+5 \mathrm{~cm}$ de $\mathrm{S}$; 9) $10 \mathrm{~cm}$ de $\mathrm{S}$ $+20 \mathrm{~cm}$ de $\mathrm{RC}+5 \mathrm{~cm}$ de $\mathrm{S}+20 \mathrm{~cm}$ de $\mathrm{RC}+5 \mathrm{~cm}$ de $\mathrm{S}$; 10) $10 \mathrm{~cm}$ de $\mathrm{S}+45 \mathrm{~cm}$ de $\mathrm{RC}+5 \mathrm{~cm}$ de $\mathrm{S}$; 11) $10 \mathrm{~cm}$ de $\mathrm{S}+40 \mathrm{~cm}$ de $\mathrm{RC}+10 \mathrm{~cm}$ de $\mathrm{S} ; 12) 10 \mathrm{~cm}$ de $\mathrm{S}$ $+35 \mathrm{~cm}$ de $\mathrm{RC}+15 \mathrm{~cm}$ de $\mathrm{S}$. Em agosto de 1993 , semearam-se 10 sementes de milho híbrido cultivar BR 201, desbastando-se para 6 plantas por vaso 5 dias após a emergência (DAE). Colheram-se duas plantas aos 30, 60 e 90 DAE para avaliação do peso de matéria seca (MS) e conteúdo de nutrientes. Foram analisados os teores totais de $\mathrm{N}, \mathrm{P}, \mathrm{Mg}, \mathrm{K}, \mathrm{S}, \mathrm{Fe}, \mathrm{Cu}, \mathrm{Zn}, \mathrm{Mn}$ e $\mathrm{Na}$ na parte aérea das plantas, segundo metodologia descrita por TEDESCO et al. (1995). Cultivaram-se 10 plantas por vaso de trevo-branco somente no bloco III, efetuando-se três cortes aos 60, 90 e 120 DAE para as mesmas avaliações feitas para o milho.

Em julho de 1995, cultivou-se aveia-preta cultivar UFRGS 10, semeando-se 50 plantas por vaso, com desbaste para 30 plantas aos 5 DAE. Foram feitas irrigações diárias e suplementações semanais de $\mathrm{N}, \mathrm{P}$ e $\mathrm{K}$ nas formas de $\mathrm{NH}_{4} \mathrm{NO}_{3}, \mathrm{NaH}_{2}$ $\mathrm{PO}_{4}$ e $\mathrm{KC} \ell$ como solução nutritiva para atingir as concentrações finais de $400 \mathrm{mg}$ de $\mathrm{N}, 80 \mathrm{mg}$ de $\mathrm{P}$ e $600 \mathrm{mg}$ de K. Aos 40 DAE, colheram-se 10 plantas por vaso para determinação do peso de matéria seca e conteúdo de $\mathrm{N}, \mathrm{P}, \mathrm{Mg}, \mathrm{K}, \mathrm{S}, \mathrm{Fe}, \mathrm{Cu}, \mathrm{Zn}, \mathrm{Mn}, \mathrm{Na}$, $\mathrm{Cd}$, $\mathrm{Ni}$ e $\mathrm{Pb}$, segundo metodologia descrita por TEDESCO et al. (1995). Em janeiro de 1996, semearam-se 10 sementes de milho híbrido cultivar PIONEER 3069, desbastando-se para 6 plantas por vaso aos 5 DAE. Foram feitas suplementações com $\mathrm{N}$, P e K, como solução nutritiva para atingir concentrações finais de $300 \mathrm{mg}$ de N, 300mg de P e 920mg de K. Aos 30, 60 e 90 DAE, colheram-se 
duas plantas por vaso para as mesmas avaliações feitas para a aveia.

A avaliação da densidade populacional de bactérias, actinomicetos e fungos foi executada pelo método de diluições sucessivas e contagem em placas de Petri. Em 1993, as amostragens foram realizadas após os cultivos de milho e trevo; em 1995, antes e após o cultivo de aveia e, em 1996 após o cultivo de milho. A coleta das amostras foi realizada em orifícios localizados a $10 \mathrm{~cm}$ do fundo dos vasos nos tratamentos 1,8 e $12 ;$ a $10 \mathrm{~cm}$ do topo do vaso no tratamento 7 e em amostra de solo sem correção.

Foi utilizada a análise de variância complementada por testes de comparações múltiplas (Tukey), ao nível de 5\% de significância, na comparação das médias de matéria seca dos cultivos e da população microbiana. Para a discussão dos resultados de concentração e extração de nutrientes e metais pesados, utilizou-se o valor médio dos tratamentos com rejeito carbonífero em comparação com o T1 (sem RC), pois não se verificaram diferenças significativas entre os tratamentos com RC.

\section{RESULTADOS E DISCUSSÃO}

\section{Crescimento de plantas}

A produção de matéria seca (MS) de plantas de trevo, milho e aveia foi afetada pela presença do rejeito carbonífero (RC) e pela espessura da camada de solo aplicada na superfície do RC (Figura 1). No T1, contendo $60 \mathrm{~cm}$ de solo corrigido, observaram-se as maiores produções de MS das plantas. No T2 $(60 \mathrm{~cm}$ de RC) e T3 $(60 \mathrm{~cm}$ $\mathrm{RC}+\mathrm{PK})$, as plântulas dos quatro cultivos morreram poucos dias após a germinação das sementes, devido à condição de elevada acidez associada ao RC, que apresentava $\mathrm{pH}$ de 3,2 na instalação do experimento (GAIVIZZO et al., 2002).

No $\mathrm{T} 5, \mathrm{com} 5 \mathrm{~cm}$ de solo corrigido aplicado sobre o RC, observaram-se as menores produções do trevo e do milho (1993) e as plântulas de aveia (1995) e milho (1996) morreram poucos dias após a germinação das sementes (Figura 1). Isto provavelmente ocorreu devido ao aumento no período de intemperização do $\mathrm{RC}$, o que ocasionou uma acidificação na interface solo/rejeito (GAIVIZZO et al., 2002), inibindo o sistema radicular das plantas. DANCER \& JANSEN (1987), num período de 13 anos, em Illinois (USA), constataram que a utilização de camada de solo com espessura de $20 \mathrm{~cm}$ minimizou o efeito da acidez do rejeito carbonífero sobre os cultivos de milho e soja, que tiveram rendimentos médios de grãos ao redor de 19 e $50 \%$, respectivamente, superiores ao cultivo direto sobre o rejeito. Para os cultivos de trevo e aveia, não houve diferenças de matéria seca entre as

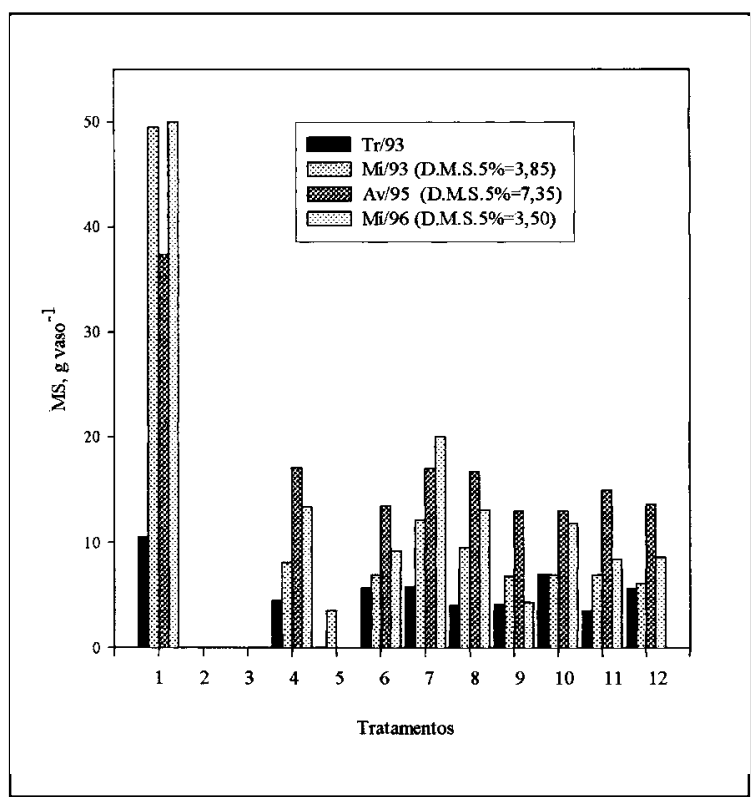

Figura 1 - Produção de matéria seca (MS) da parte aérea de plantas de trevo (Tr/93) e milho (Mi/93) em 1993, aveia (Av/95) em 1995 e milho (Mi/96) em 1996, cultivadas em colunas com diferentes camadas de solo (S) e rejeito carbonífero (RC): 1) $60 \mathrm{~cm}$ de $S ; 2$ ) $60 \mathrm{~cm}$ de RC; 3) $60 \mathrm{~cm}$ de RC + adubo PK; 4) $10 \mathrm{~cm}$ de $\mathrm{S}+1 \mathrm{~cm}$ de calcário $+49 \mathrm{~cm}$ de RC; 5) $5 \mathrm{~cm}$ de $\mathrm{S}+$ $55 \mathrm{~cm}$ de RC; 6) $10 \mathrm{~cm}$ de $\mathrm{S}+50 \mathrm{~cm}$ de RC; 7) $15 \mathrm{~cm}$ de $\mathrm{S}+45 \mathrm{~cm}$ de $\mathrm{RC} ; 8) 10 \mathrm{~cm}$ de $\mathrm{S}+45 \mathrm{~cm}$ de mistura $1 \mathrm{~S}: 1 \mathrm{RC}+5 \mathrm{~cm}$ de $\mathrm{S}$; 9) $10 \mathrm{~cm}$ de $\mathrm{S}+20 \mathrm{~cm}$ de $\mathrm{RC}+$ $5 \mathrm{~cm}$ de $\mathrm{S}+20 \mathrm{~cm}$ de $\mathrm{RC}+5 \mathrm{~cm}$ de $\mathrm{S} ; 10) 10 \mathrm{~cm}$ de $\mathrm{S}$ $+45 \mathrm{~cm}$ de $\mathrm{RC}+5 \mathrm{~cm}$ de $\mathrm{S} ; 11) 10 \mathrm{~cm} \mathrm{de} \mathrm{S}+40 \mathrm{~cm} \mathrm{de}$ $\mathrm{RC}+10 \mathrm{~cm}$ de $\mathrm{S} ; 12) 10 \mathrm{~cm}$ de $\mathrm{S}+35 \mathrm{~cm}$ de $\mathrm{RC}+$ $15 \mathrm{~cm}$ de $\mathrm{S}$.

camadas de 10 e $15 \mathrm{~cm}$, sugerindo que uma camada de $10 \mathrm{~cm}$ seria considerada como a mínima necessária para promover o estabelecimento dessas espécies (Figura 1). No T7, a utilização de uma camada de $15 \mathrm{~cm}$ de solo sobre o RC proporcionou as maiores produções de MS dos cultivos de milho. Isto provavelmente ocorreu devido ao elevado porte da cultura, necessitando de camadas de solo mais espessas para a sua sustentação. No entanto, observou-se que, apesar do aumento da produção de MS, em função do aumento da espessura da camada de solo, as plantas de milho tiveram seu desenvolvimento bastante prejudicado, apresentando sintomas de deficiência de $\mathrm{N}$ e $\mathrm{P}$. As plantas também foram prejudicadas pela baixa disponibilidade de água na camada de solo, apesar das irrigações diárias. Portanto, o uso de espécies com hábito de crescimento ereto e de alto porte é desaconselhável nos estágios iniciais de recolonização de áreas reconstruídas.

$\mathrm{O} \mathrm{T} 4$, contendo uma camada de $1 \mathrm{~cm}$ de calcário entre a camada de $10 \mathrm{~cm}$ de solo e o $\mathrm{RC}$, parece ter atenuado o efeito da acidez sobre o desenvolvimento das raízes nos cultivos de aveia e 
milho (1996). O tratamento 8 , com $10 \mathrm{~cm}$ de solo sobre uma mistura $(1: 1)$ de RC e solo, também parece ter atenuado os efeitos da interface solo/rejeito sobre as raízes. TEIXEIRA et al. (1995), em Butiá, RS, observaram que a utilização de uma camada de cinzas ( $\mathrm{pH}$ de 8,4) entre o solo e o rejeito carbonífero proporcionou aumento nos rendimentos dos cultivos de inverno e verão. DANIELS (1996) também recomenda a utilização de uma camada de calcário entre o solo e o RC, principalmente quando este apresentar elevado potencial de acidificação. O autor salienta que a determinação da espessura da camada de corretivo deve basear-se no potencial de acidificação do rejeito.

A utilização de camadas de solo em posição de subsuperfície e alternadas ao rejeito não afetou o rendimento dos cultivos, uma vez que não houve penetração das raízes no RC. Ressalta-se ainda que os efeitos negativos do RC sobre o desenvolvimento do sistema radicular das plantas deveram-se, além do baixo $\mathrm{pH}$, à elevada concentração de íons na solução do solo reconstruído, principalmente de metais pesados resultantes da dissolução dos sulfetos e de outros minerais presentes no rejeito (GAIVIZZO et al., 2002).

Extração de nitrogênio, fósforo, potássio, cálcio, magnésio e sódio

Observa-se, na figura 2, que a extração de $\mathrm{N}, \mathrm{P}, \mathrm{K}, \mathrm{Ca}$ e $\mathrm{Mg}$ pelos cultivos foi menor nos tratamentos com rejeito carbonífero(com RC) em relação ao $\mathrm{T} 1$ (sem RC). Isto ocorreu devido ao menor volume de solo explorado pelo sistema radicular das culturas nos tratamentos com RC. O baixo $\mathrm{pH}$ e a elevada concentração de íons solúveis resultantes do $\mathrm{RC}$ limitaram o crescimento das raízes e a utilização de N, P e K das camadas de solo subsuperficiais e alternadas ao rejeito e restringiram o aproveitamento dos nutrientes adicionados como solução nutritiva durante os cultivos de aveia e milho (1996). Contudo, constata-se que, apesar do pequeno aproveitamento desses nutrientes, a adição da solução nutritiva, em 1995 e 1996, possibilitou que esses cultivos extraíssem maiores quantidades de N, P e K, principalmente a aveia, que apresentou a maior produção de MS, devido a sua boa capacidade de adaptação em ambientes adversos.

Concentração e extração de enxofre, ferro, cobre, zinco, manganês, cádmio, níquel e chumbo

A concentração de $\mathrm{S}$ nos tratamentos com rejeito carbonífero (com RC) foi maior do que no T1 (sem RC) nas plantas de trevo, aveia e milho (1996) (Figura 3); em 1993, a concentração de S nas plantas de milho nos tratamentos com e sem RC não diferiram entre si. $\mathrm{O}$ melhor desenvolvimento das

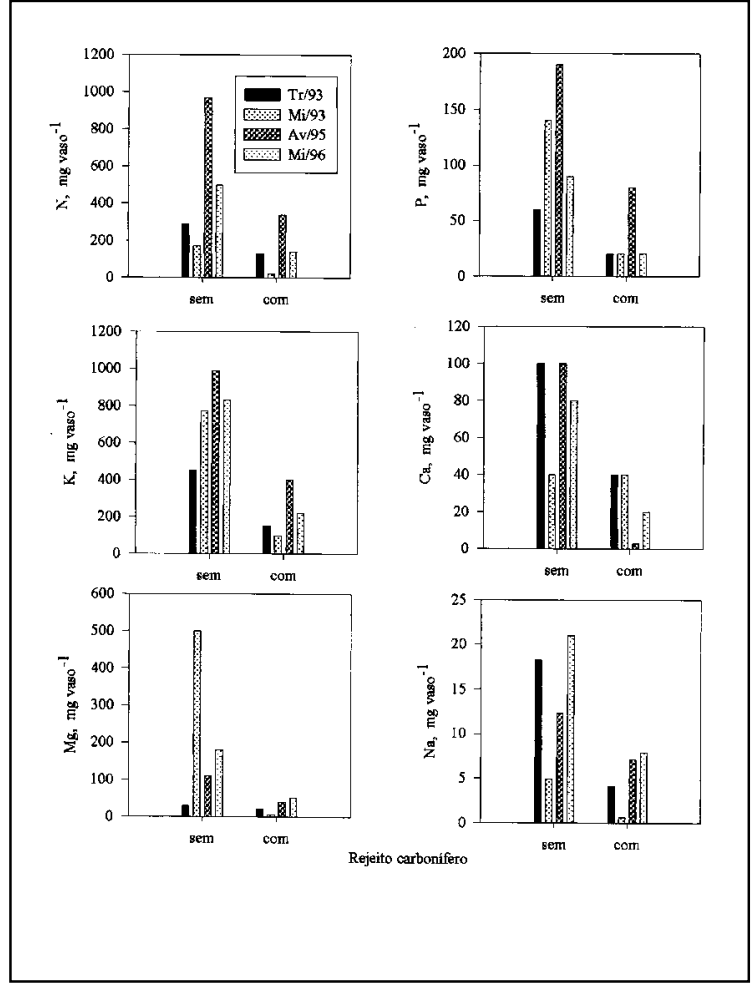

Figura 2 - Extração de N, P, K, Ca, Mg e Na pela parte aérea de plantas de trevo (Tr/93) e milho (Mi/93) em 1993, aveia (Av/95) em 1995 e milho (Mi/96) em 1996, cultivadas em colunas sem rejeito carbonífero (RC) e com RC (média de 11 tratamentos).

plantas no T1 (Figura 1) causou extrações de $\mathrm{S}$ maiores do que nos tratamentos com RC (Figura 4). Em 1995 e 1996, as culturas extraíram maiores quantidades de $\mathrm{S}$. $\mathrm{Na}$ presença do $\mathrm{RC}$, isto provavelmente ocorreu em função da maior disponibilidade do elemento na interface solo/rejeito devido ao aumento no período de intemperização do RC (GAIVIZZO et al., 2002).

A concentração de $\mathrm{Fe}$ nas plantas de trevo e aveia foi superior nos tratamentos com RC, enquanto nas plantas de milho, em 1993, houve menor concentração na presença do RC, e em 1996 os resultados não diferiram do $\mathrm{T} 1$ (Figura 3). A elevada capacidade de extração de $\mathrm{Fe}$ pelo trevo (Figura 4), deve-se provavelmente à maior extração de nutrientes pelas raízes, ocasionada pelo melhor suprimento de $\mathrm{N}$ pelos nódulos, enquanto a da aveia deve estar relacionada com o denso sistema radicular e a maior disponibilidade do elemento na interface solo/rejeito.

As concentrações de $\mathrm{Cu}, \mathrm{Zn}$ e $\mathrm{Mn}$ nas plantas de trevo, milho e aveia foram maiores nos tratamentos com rejeito carbonífero do que no $\mathrm{T} 1$, contendo apenas solo (Figura 3). Em 1995 e 1996, as 


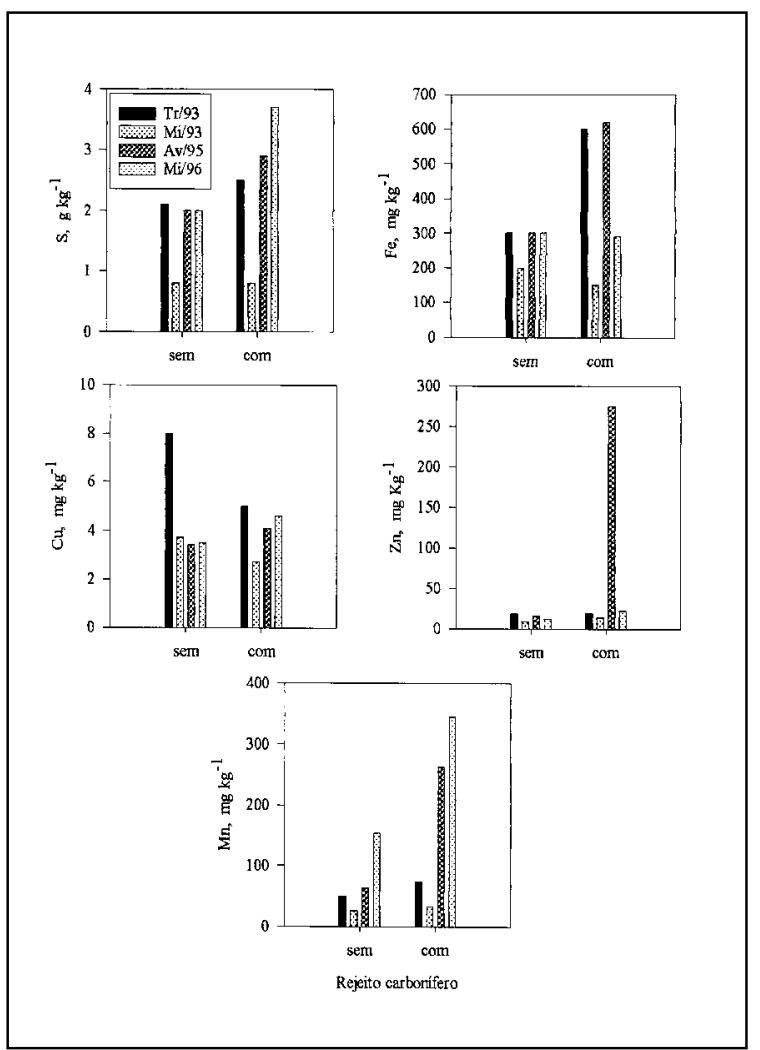

Figura 3 - Concentração de S, Fe, Cu, Zn e Mn na parte aérea de plantas de trevo (Tr/93) e milho (Mi/93) em 1993, aveia (Av/95) em 1995 e milho (Mi/96) em 1996, cultivadas em colunas sem rejeito carbonífero (RC) e com RC (média de 11 tratamentos).

culturas (aveia e milho) extraíram maiores quantidades de $\mathrm{Cu}, \mathrm{Zn}$ e $\mathrm{Mn}$ em relação a 1993 (trevo e milho) (Figura 4). Isto ocorreu devido à continuidade das reações de oxidação da pirita, com conseqüente acidificação da interface solo/rejeito, aumentando a disponibilidade dos elementos nesse período. Analisando os dados de concentração de $\mathrm{Cu}, \mathrm{Zn}$ e $\mathrm{Mn}$ em 1993, nas plantas de trevo e milho (Figura 3), constata-se que mesmo nesse período a disponibilidade desses elementos na interface solo/rejeito já era elevada, o que está de acordo com a caracterização química do RC na instalação do experimento e com os dados de lixiviação (GAIVIZZO et al., 2002).

As determinações de $\mathrm{Cd}$, $\mathrm{Ni}$ e $\mathrm{Pb}$ foram realizadas apenas nas plantas de aveia e milho (1996). Os tratamentos com rejeito carbonífero apresentaram maiores concentrações desses elementos em relação ao T1 (Figura 5). Este comportamento evidencia elevada concentração de metais pesados solúveis na interface solo/rejeito. Apesar dos metais pesados analisados no presente estudo ( $\mathrm{Fe}, \mathrm{Cu}, \mathrm{Zn}, \mathrm{Mn}, \mathrm{Cd}, \mathrm{Ni}, \mathrm{Pb}$ ) terem sido mobilizados em elevadas quantidades na água de

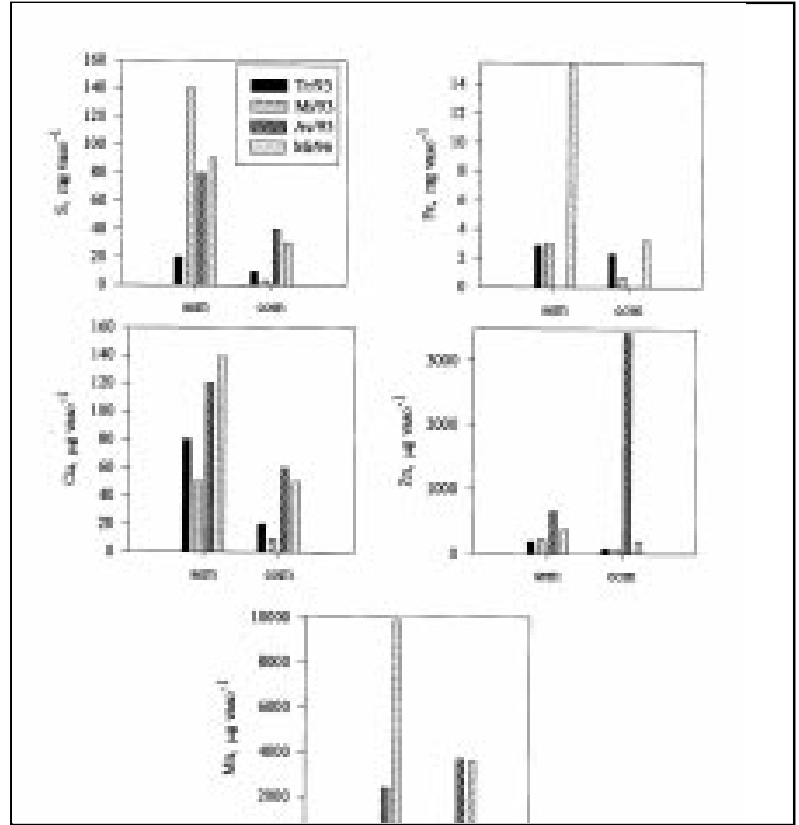

Figura 4 - Extração de $\mathrm{S}, \mathrm{Fe}, \mathrm{Cu}, \mathrm{Zn}$ e Mn pela parte aérea de plantas de trevo (Tr/93) e milho (Mi/93) em 1993, aveia (Av/95) em 1995 e milho (Mi/96) em 1996, cultivadas em colunas sem rejeito carbonífero (RC) e com RC (média de 11 tratamentos)

lixiviação, principalmente o $\mathrm{Fe}, \mathrm{Zn}, \mathrm{Mn}, \mathrm{Ni}$ e $\mathrm{Pb}$ (GAIVIZZO et al., 2002), indicando sua elevada disponibilidade na interface solo/rejeito para serem absorvidos pelas plantas, constata-se que suas concentrações no tecido vegetal situaram-se abaixo dos limites considerados tóxicos ou excessivos (KABATA-PENDIAS \& PENDIAS, 1986). Este comportamento também foi observado por JOOST et al. (1987) e PICHTEL et al. (1989).

\section{Microbiota do solo}

A microbiota do solo foi sensivelmente afetada pela presença do rejeito carbonífero. As menores populações de bactérias, actinomicetos e fungos ocorreram nos tratamentos com mistura solo/rejeito e solo abaixo do rejeito, amostrados a $10 \mathrm{~cm}$ do fundo do vaso (Tabela 1). Esses resultados refletem a interação da drenagem ácida proveniente do rejeito com o solo durante as lixiviações. De acordo com TSAI et al. (1992), a inibição do crescimento microbiano em valores baixos de $\mathrm{pH}$ resulta não só da elevada concentração de $\mathrm{H}^{+}$, como também da influência direta do $\mathrm{pH}$ na penetração de compostos tóxicos do meio nas células microbianas. No tratamento solo acima do rejeito, amostrado a $10 \mathrm{~cm}$ do topo do vaso, as populações de bactérias e fungos foram menores que nos tratamentos solo não corrigido e $60 \mathrm{~cm}$ de solo corrigido, amostrado a $10 \mathrm{~cm}$ do fundo do vaso, enquanto a população de

Ciência Rural, v. 32, n. 6, 2002. 


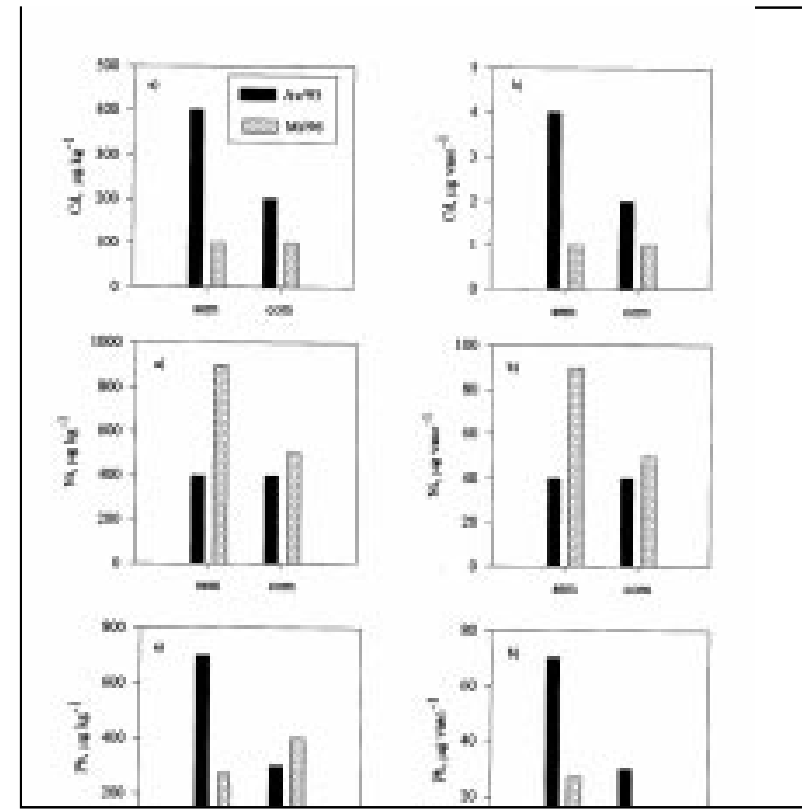

Figura 5 - Concentração (a) e extração (b) de $\mathrm{Cd}, \mathrm{Ni}$ e $\mathrm{Pb}$ pela parte aérea de plantas de aveia (Av/95) em 1995 e milho (Mi/96) em 1996, cultivadas em colunas sem rejeito carbonífero (RC) e com RC (média de 11 tratamentos).

actinomicetos foi semelhante nesses tratamentos. Este comportamento provavelmente se deve à maior variação de temperatura na parte superior dos vasos. Os esporos dos actinomicetos apresentam um alto grau de resistência à dessecação e persistem à ação de altas temperaturas durante períodos maiores que os outros grupos microbianos (ALEXANDER, 1980).
1) Não há o estabelecimento de plantas de trevo, milho e aveia semeadas diretamente na superfície do rejeito carbonífero;

2) uma camada de solo de $10 \mathrm{~cm}$ sobre a superfície do RC é a mínima necessária ao estabelecimento de trevo e aveia;

3) a pequena espessura ( 5 a $15 \mathrm{~cm})$ das camadas de solo sobre o rejeito carbonífero limita o desenvolvimento radicular e a extração de $\mathrm{N}, \mathrm{P}$, $\mathrm{Na}, \mathrm{K}, \mathrm{Ca}$ e $\mathrm{Mg}$ pela parte aérea das plantas de trevo, milho e aveia;

4) os teores de $\mathrm{S}, \mathrm{Fe}, \mathrm{Cu}, \mathrm{Zn}, \mathrm{Mn}, \mathrm{Cd}, \mathrm{Ni}$ e $\mathrm{Pb}$ na parte aérea das plantas de trevo, milho e aveia são maiores na presença do rejeito carbonífero, mas situam-se abaixo dos limites considerados tóxicos a estas espécies;

5) a elevada acidificação devida ao rejeito carbonífero e a solubilização de metais reduz a densidade populacional de bactérias, actinomicetos e fungos, principalmente nas camadas de solo de subsuperfície.

\section{REFERÊNCIAS BIBLIOGRÁFICAS}

\author{
ALEXANDER, M. Introduction to soil \\ microbiology. 2.ed. New York : J. Wiley, \\ 1980. 472p. \\ DANIELS, W.L., AMOS, D.F. Generating \\ Productive topsoil substitutes from hard rock \\ overburden in the Southern Appalachians. \\ Environmental Geochemistry and Health, \\ v.7, p.8-15,1985.
}

DANIELS, W. L. Manipulating the chemical properties of mine soils and mining wastes. In: O SOLO NOS GRANDES DOMÍNIOS MORFOCLIMÁTICOS DO BRASIL EO DESENVOLVIMENTO SUSTENTADO, 1995, Viçosa. Anais... Viçosa : SBCS, UFV, DPS, 1996. p.867-897.

DANCER, W.S., JANSEN, I.J. Minespoil acidity and rowerop productivity. Journal of Environmental Quality, v.16, n.3, p.242246, 1987.

GAIVIZZO, L.H.B., VIDOR, C., TEDESCO, M.J. et al. Potencial poluidor de rejeitos carboníferos. I. Caracterização química da água de lixiviação. Ciência Rural, Santa Maria, v.32, n.5, p.771-780, 2002.

Ciência Rural, v. 32, n. 6, 2002. 
JOOST, R.E., OLSEN, F.J., JONES J.H. Revegetation and minesoil development of coal refuse amended with sewage sludge and limestone. Journal of Environmental Quality, Madison, v.16, n.1, p.65-68, 1987.

KABATA-PENDIAS, A., PENDIAS,H. Trace elements in soils and plants. Florida: RC, 1986. 315p.

PICHTEL, J.R., DICK, W.A., McCOY, E.L. Binding of iron from pyritic mine spoil by water-soluble organic materialsextracted from sewage sludge 3. Soil Science, Baltimore, v.148, n.2, p.140-148, 1989

SILVA, Z.C.C. Jazidas de carvão no Rio grande do Sul, Brasil. In: SIMPÓSIO BRASILEIRO DE GEOLOGIA, 1987, Curitiba. Atas... Curitiba: 1987. V.2, p.677-886.

TAYLOR, R.W., IBEABUCHI, I.O., SISTANI, K.R. $\boldsymbol{e}$ t al Accumulation of some metals by legumes and their extractability from acid mine spoils. Journal of
Environmental Quality, Madison, v.21, n.2, p.176-180, 1992.

TEDESCO, M.J., GIANELlO, C., BISSANI, C.A. et al. Análises de solos, plantas e outros materiais. 2.ed. Porto Alegre : Departamento de Solos - UFRGS, 1995. 174p. (Boletim Técnico, 5).

TEIXEIRA, E.C., TEDESCO, M.J. BUGIN, A., et al. Utilização de cinzas e lama-cal na recuperação de área ocupada com resíduo carbonífero. Porto Alegre : FAPERGS, 1995. 3 p. (Relatório Técnico).

TSAI, S.M. Efeito de fatores do solo. In: BRANDÃO, E.J.B.N., TSAI, S.M., NEVES, M.C.P. (Coord.). Microbiologia do solo. Campinas : SBCS, 1992. 360p.

VIDOR, C. Rejeitos de minas de carvão. In: TEDESCO, M.J., GIANELLO, C. Utilização de resíduos. Porto Alegre: UFRGS, 1996. p.114-132. (não publicado). 